\title{
A Study on the Emotional Intelligence Level, Academic Pressure and Academic Performance of Basic Nursing Students in Hardwani Nursing College
}

\author{
Gahok Kvmar \\ Quadra Institute of Nursing, Roorkee, India
}

\begin{abstract}
Stress in nursing education is acknowledged as one of the most important issues in the present time. The challenges in nursing curriculum can be very stressful for nursing students. This may affect their academic performance. It was identified that emotional intelligence of an individual, plays vital role in managing academic stress. Entitled A study to assess the level of emotional intelligence, academic stress and academic performance of Basic B.sc Nursing students in a selected Nursing college, Haldwani Objectives of the study: • To assess the level of Emotional Intelligence, Academic Stress and Academic Performance $\bullet$ To find out the corelation between level of Emotional Intelligence, level of Academic Stress and Academic Performance Research Method Quantitative approach with descriptive research design was adopted; Through Purposive sampling techniques, 140 samples were selected from a selected Nursing College of Haldwani. Validated questionnaire tool on emotional intelligence and academic stress was used to collect data. Academic performance of students was collected based on the internal assessment marks. Academic performance of students was taken from teacher of respective class. Later, data was analyzed using inferential and descriptive statistics. Findings: Most of the (47.2 $\%$ ) study participants were in the age group of 19 to 20 years. Maximum (86.4\%) of the study participants were Hindus. The analysis of results revealed that, there was a $(r=-0.810)$ strong negative correlation existed between emotional intelligence and academic stress. Similarly, a weak positive correlation $(r=0.291)$ existed between emotional intelligence and academic performance. Conclusion: The whole study was cost effective, simple and carried out in an acceptable way. Findings of this study concluded that students with good emotional intelligence had highest number in low academic stress score and had good academic performance.
\end{abstract}

Keywords: Emotional Intelligence, Academic Stress, Academic Performance

\section{Introduction}

"Stress is the trash of modern life we all generate it but if you don't dispose of it properly, it will pile up and overtake your life" -Danzae Pace

In the current competitive environment where students are expected multi roles with efficiency and effectiveness, it is highly needed to develop their right attitudes and emotional intelligence towards the unseen complexities of life and quality education. Stress in nursing education is acknowledged as one of the most important issues in the present time. The challenges in nursing curriculum can be very stressful for nursing students. This may affect their academic performance. It was identified that emotional intelligence of an individual, plays vital role in managing academic stress

\section{Research Statement}

A study to assess the level of emotional intelligence, academic stress and academic performance of Basic B.sc Nursing students in a selected Nursing college, Haldwani

Objectives of the study

- To assess the level of Emotional Intelligence, Academic Stress and Academic Performance

- To find out the co-relation between level of Emotional Intelligence, level of Academic Stress and Academic Performance

\section{Literature}

Many studies have found a relationship between stress and poor academic performance. Bell (1995), Dubois \& Felner (1992) and Ganesan (1995) found that, stress made a significant contribution in poor academic performance. In one of the studies, a significant negative correlation was found between the stress levels of college students and their academic performance

\section{Methodology}

Quantitative approach with descriptive research design was adopted; Through Purposive sampling techniques, 140 samples were selected from as selected Nursing College of Haldwani. Validated questionnaire tool on emotional intelligence and academic stress was used to collect data. Academic performance of students was collected based on the internal assessment marks. Academic performance of students was taken from teacher of respective class. Later, data was analyzed using inferential and descriptive statistics.

\section{Results}

Most of the (47.2\%) study participants were in the age group of 19 to 20 years. Maximum (86.4\%) of the study participants were Hindus. The analysis of results revealed that, there was a $(r=-0.810)$ strong negative correlation existed between emotional intelligence and academic stress. This indicated that as emotional intelligence increased the 
level of academic stress experienced by the students reduced.

Similarly, a weak positive correlation $(r=0.291)$ existed between emotional intelligence and academic performance. Finally, a correlation between academic stress and academic performance revealed negative correlation significance level $<0.01$. Hence the researcher accepted the research hypothesis $\mathrm{H}_{1}, \mathrm{H}_{2}$ and $\mathrm{H}_{3}$ and rejected the null hypothesis.

\section{Conclusion}

The whole study was cost effective, simple and carried out in an acceptable way. Findings of this study concluded that students with good emotional intelligence had highest number in low academic stress score and had good academic performance. Whereas, students with low emotional intelligence had high level of academic stress in specific areas and performed poorly in academic performance evaluation.

\section{References}

[1] Steven L. Bernstein MD. The Effect of Emergency Department Crowding on Clinically Oriented Outcomes. S A E [internet] 2008 December 29 [citied 2017 Jun 15] vol.8, no.3 pp. 21-32 available from https://doi.org/10.1111/ j.1553-2712.2008.00295.html.

[2] Dr. P Suresh Prabu. A Study on Academic Stress among Higher Secondary Students International Journal of Humanities and Social Science Invention[internet] 2015 October[citied 2017 Jun 15] Volume 4 Issue 10 PP.6368 available from- http//.ijhssi.org.html 